\title{
Transformaciones en la concepción iusinternacionalista del Estado constitucional en un contexto de globalización de la justicia penal internacional
}

\author{
Daniel García San José \\ Profesor Titular de Derecho Internacional Público y de Relaciones Internacionales \\ Universidad de Sevilla
}

Recibido: 01.10.2012

Aceptado: 15.10.2012

Resumen: Se aborda un tema clásico desde una perspectiva novedosa: la conceptualización en Derecho Internacional del Estado constitucional en un marco jurídico en el que los atributos inherentes a la soberanía estatal interactúan con las obligaciones imperativas relativas a la represión y castigo de los autores de graves crímenes contra el Derecho Internacional. Desde esta aproximación se defiende la tesis de que se está postulando desde los últimos años un concepto de Estado constitucional, de validez universal, sustentado sobre el triple eje de la legitimidad de los gobernantes, la intangibilidad de los derechos humanos fundamentales y la rendición internacional de cuentas.

Palabras clave: Soberanía, Estado Constitucional, Justicia Penal Internacional, Derechos Humanos, Gobernanza.

Abstract: In these pages we face a classical topic from a new approach: the concept of constitutional State under International Law where the power inherent to sovereignty are to be exercised at the same level than the imperative duties for States to prosecute and punish those authors of international crimes. Under this approach, it is defended the thesis that the concept of constitutional state worldwide postulated in the latest years is based upon a three-pillar-idea of legitimacy, intangibility and accountability.

Key words: Sovereignty, Constitutional State, International Penal Justice, Human Rights, Governance.

Sumario: 1. Introducción.-2. Un tema clásico objeto de relectura: la soberanía estatal. - 3. El contexto de contexto de obligaciones imperativas para los Estados en materia de represión y sanción de los graves crímenes contra el Derecho Internacional.-3.1. Los antecedentes lejanos.-3.2. Los antecedentes recientes.-3.3. Significado y alcance de la justicia penal internacional en un proceso de reconstrucción internacional de un Estado constitucional. - 4. Los vectores de un nuevo paradigma internacional de Estado constitucional. - 4.1. La legitimidad de los gobernantes (legitimacy). - 4.2. La intangibilidad de los derechos humanos fundamentales (intangibility of human rights). - 4.3. La rendición internacional de cuentas (accountability). - 5. Conclusiones. 


\section{INTRODUCCIÓN}

En estas páginas se aborda un tema clásico pero desde una perspectiva novedosa: la conceptualización en Derecho Internacional de un modelo de Estado constitucional en el que el papel de la soberanía ha de ejercerse en un contexto de obligaciones imperativas para los Estados en materia de represión y sanción de los graves crímenes contra el Derecho Internacional. Desde esta perspectiva, la tesis que defiendo es que se asiste a una relectura de este concepto a partir de un triple eje: a) la legitimidad de los gobernantes (legitimacy); b) la intangibilidad de los derechos humanos fundamentales (intangibility); c) la rendición internacional de cuentas (accountability).

\section{UN TEMA CLÁSICO OBJETO DE RELECTURA: LA SOBERANÍA ESTATAL}

En un medio social escasamente vertebrado y poco institucionalizado como es la sociedad internacional, la soberanía de los Estados sigue siendo un principio constitucional ${ }^{1}$. La sociedad pos internacional ${ }^{2}$, mucho más compleja e insegura que la anterior a los atentados del 11 de Septiembre de 2001, no ha supuesto un cambio de ruptura con los paradigmas de sociedad-comunidad internacionales pasados sino una constante de cambio y permanencia de manera que hoy día es posible identificar, siguiendo al profesor Carrillo Salcedo hasta tres concepciones de la sociedad internacional según que ésta se constituya en función de una simple yuxtaposición de Estados soberanos, del reconocimiento de la existencia de unos intereses comunes de los Estados o, por último, de una organización internacional diferenciada, esto es, de la cooperación permanente e institucionalizada entre los Estados ${ }^{3}$.

Así pues, en el mundo globalizado en que vivimos, el paradigma de sociedad internacional coexiste con el de comunidad internacional. Ahora bien, para que exista una comunidad internacional es indispensable la presencia de intereses comunes así como un patrimonio común de valores. En este sentido, uno de los indicios que mejor reflejan la idea de comunidad internacional pos contemporánea es la nueva concepción de la soberanía que se hace responsable. El antiguo Secretario General de Naciones Unidas, Kofi Annan, en su informe Un concepto más amplio de la libertad: desarrollo, seguridad y

${ }^{1}$ Carrillo Salcedo, J. A., Curso de Derecho Internacional Público, Tecnos, Madrid, 1992, p. 20.

${ }^{2}$ Ibáñez Muñoz, J., «La sociedad pos internacional», García Segura, C., Vilariño Pintos, E. (Coords.), Comunidad Internacional y Sociedad Internacional después del 11 de septiembre de 2001, Centro de Investigación para la Paz, Guernica, 2005, pp. 119 a 130.

${ }^{3}$ CARrillo Salcedo, J. A., «La Comunidad internacional entre la ilusión y la Historia», Casado Raigón, R., Gallego Domínguez, I. (Coords.), Personalidad y capacidad jurídica, Servicio de publicaciones de la Universidad de Córdoba, Córdoba, 2005, p. 290. 
derechos humanos para todos, de 21 de marzo de 2005, lo ponía de manifiesto al señalar que la nueva lectura de la soberanía -coherente con esta idea de comunidad internacional- exigía:

«la rendición de cuentas de los Estados ante sus ciudadanos, de los Estados entre sí, de las instituciones internacionales ante sus miembros

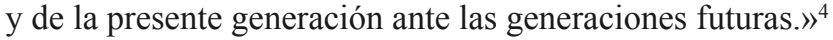

La rendición de cuentas supone, así pues, la asunción de obligaciones de cada Estado con sus ciudadanos, con otros Estados, con el conjunto institucionalizado de Estados en Organizaciones Internacionales, y con las generaciones futuras que habrán de reemplazarnos en el tiempo. Desde esta relectura de la soberanía, ésta se ha puesto en cuestión en su dimensión tradicional respecto de los conocidos como «Estados fallidos» carentes, en muchas ocasiones, de todo tipo de organización política y con desplazamientos masivos de poblaciones que buscan refugio en otros Estados ${ }^{5}$. Igualmente, y de un modo más general, la nueva lectura de la soberanía podría servir en potencia para cuestionar la posición de autosuficiencia de cualquier Estado del planeta ${ }^{6}$. En resumen, frente a un modelo clásico de análisis formalista-descriptivo de la soberanía estatal, parece insistirse ahora desde un prisma diferente que pudiera denominarse funcionalista-conceptual, en formular la pregunta: «¿qué es un Estado soberano?» Subyacente a esta pregunta se encontraría, al igual que en la aproximación tradicional, una premisa: la soberanía estatal no sería, hoy día, tanto un estatuto espacial y temporal como una actitud vital que, por ejemplo, exigiría no hacer derivar automáticamente la plena personalidad jurídica y capacidad de obrar en el ámbito internacional de tener un territorio, un gobierno efectivo y una población. En otras palabras, desde esta perspectiva funcionalista-conceptual de la soberanía estatal, habría que prestar atención no solo al cumplimiento formal de unos requisitos sino al ejercicio de unos derechos y deberes derivados del estatus internacional que presuponen dichos requisitos.

La relectura de la soberanía como soberanía responsable en una perspectiva esencialmente funcional conlleva el hecho de que los propios Estados soberanos aparezcan, cada vez más, en el doble papel de instituciones de au-

${ }^{4}$ NACIONES Unidas, Un concepto más amplio de la libertad: desarrollo, seguridad y derechos humanos para todos, informe del Secretario General de Naciones Unidas de 21 de marzo de 2005, parágrafo 22.

${ }^{5}$ Márquez Botella, D., Ruiloba García, E., Torres Cazorla, Ma . I., García Rico, E., Martín Martínez, M., Salinas de Frías, A., Rodríguez Carrión, A., "Los sujetos del Derecho internacional en un mundo en transformación», Persona y Estado en el umbral del siglo XXI, XX Aniversario de la Facultad de Málaga, Málaga, 2002, pp. 491 y 493.

${ }^{6}$ Como lo expresó el Secretario General de Naciones Unidas en su referido informe de 21 de marzo de 2005, Un concepto más amplio de la libertad: desarrollo, seguridady derechos humanos para todos. Parágrafo 24 del Informe, Doc. A/59/2005. 
toridad (en términos de jurisdicción interna) y de agentes de garantía del cumplimiento de referencias normativas internacionales, cuyos poderes se encuentran desde el principio definidos en función del cumplimiento del interés de la Comunidad Internacional en su conjunto ${ }^{7}$. De nuevo en esta relectura de la soberanía, la rendición de cuentas deviene esencial ${ }^{8}$. La idea de la soberanía responsable en la que el principio de la rendición de cuentas deviene esencial me parece más idónea para el momento actual de las relaciones internacionales que otras relecturas de esta institución, como la sostenida por parte de la doctrina estadounidense al defender el concepto de la soberanía desagregada. Este nuevo modelo de soberanía sustentado sobre el paradigma liberal del laissez-faire, laissez-paser y sin ninguna fuerza constriñente más que la de la propia autorregulación del sistema, es caracterizado como

«la capacidad de participar en instituciones internacionales de todo tipo, en un esfuerzo colectivo para tratar problemas globales y regionales junto a sus contrapartes a nivel nacional y supranacional. La clave está en la interdependencia: que se refiere a una condición general en la que los Estados son mutuamente dependientes y vulnerables a lo que los otros Estados hacen (tradicionalmente como una separación, autonomía) y ahora como conexión, interacción. La soberanía como autonomía no tiene sentido. La nueva soberanía es estatus, «membership» pertenencia a algo, formar parte de algo, conexión al resto del mundo y la capacidad política para ser actor en el mismo.» ${ }^{9}$

Frente a cualquier crítica que apunte al riesgo de que desagregar el Estado y la concesión de un margen de soberanía a sus componentes debilitaría al Estado, autores como la profesora Slaughter, han reaccionado señalando que producirá el efecto contrario:

«Aumentará el poder del Estado como primer actor en el sistema internacional. Dando a cada institución gubernamental una medida de autoridad legítima bajo el Derecho internacional, acompañado de deberes, marca a los agentes gubernamentales como distintivo en unas políticas de redes más amplias y permite al Estado extender su alcance». ${ }^{10}$

Quizá, consciente de la fragilidad de la propuesta avanzada, la propia autora advierte el que parece ser su «talón de Aquiles» al señalar que:

${ }^{7}$ Pureza, J. M., El patrimonio común de la Humanidad, Trotta, Madrid, 2003, p. 381.

${ }^{8}$ NaCiOnes Unidas, Un concepto más amplio de la libertad: desarrollo, seguridad y derechos humanos para todos, op. cit., parágrafo 22.

${ }^{9}$ Slaughter, A.-M., A New World Order, Princeton University Press, Princeton, 2004, p. 267.

${ }^{10}$ Ibidem, p. 269. 
«Para ser efectivo, sin embargo, tendría que ser un orden mundial justo, tan inclusivo, respetuoso, tolerante e igualitario como sea posible.»111

La realidad de los últimos años mostró -especialmente durante la presidencia de G. W. Bush- que los Estados Unidos en su nuevo papel de hegemón pretendieron alterar el orden internacional en cuatro aspectos, señalados por la profesora García Segura ${ }^{12}$. En primer lugar, se buscó cambiar el propósito moral de la estructura constitucional basándolo en razones que sólo obedecen a las ideas y a los intereses estadounidenses y elevando a valores universales los propios, sin consenso y con carácter excluyente. A partir de ahí se ha tratado de modificar la identidad de los actores legítimos: ya no son los Estados sino los actores que se conforman a los valores estadounidenses. En segundo lugar, se proclamó el principio de la soberanía limitada, según el cual, la soberanía deja de ser consustancial al Estado y pasa a ser un atributo que depende de la relación de los Estados con el hegemon. En tercer lugar, se alteraron los principios y normas de conducta correcta de los Estados en la esfera internacional, ampliándose los supuestos de recurso al uso de la fuerza por parte de los Estados: guerras justas, legítima defensa preventiva y legítima defensa anticipatoria. En cuarto lugar, finalmente, Estados Unidos despreciaron dos de las instituciones básicas de la sociedad internacional: el multilateralismo y el Derecho internacional.

En mi opinión, la soberanía estatal -en su nueva relectura como soberanía responsable - sigue constituyendo la piedra de toque del orden internacional legal, legítimo y eficaz, que el Derecho internacional debe contribuir a establecer en nuestros días. De este modo, el tradicional sistema sustentado sobre la soberanía estatal seguirá siendo, para los que no comparten las tesis neoliberales del Derecho Internacional, el sistema más realista para tratar las desigualdades que aún perduran entre los participantes en las relaciones internacionales ${ }^{13}$, aunque -como propone el profesor Pureza-redefiniendo la soberanía estatal en una perspectiva esencialmente funcional. De esta manera, los Estados soberanos aparecerían, cada vez más, en el doble papel de instituciones de autoridad (en términos de jurisdicción interna) y de agentes de garantía de cumplimiento de referencias normativas internacionales ${ }^{14}$, como las que se refieren a la represión y sanción de los graves crímenes contra el Derecho internacional.

${ }^{11}$ Ibidem, p. 271.

${ }^{12}$ García Segura, C., «Sociedad internacional o desorden mundial después del 11 de septiembre de 2001», Comunidad Internacional y Sociedad Internacional después del 11 de septiembre de 2001, op. cit., pp. 70-71.

${ }^{13}$ Kingsbury, B., «Sovereignty and Inequality», European Journal of International Law, Vol. 9, 1998, p. 625.

${ }^{14}$ Pureza, J. M., El Patrimonio Común de la Humanidad. Op. cit., p. 381. 


\section{EL CONTEXTO DE OBLIGACIONES IMPERATIVAS PARA LOS ES- TADOS EN MATERIA DE REPRESIÓN Y SANCIÓN DE LOS GRA- VES CRÍMENES CONTRA EL DERECHO INTERNACIONAL}

\subsection{Los antecedentes lejanos}

En el contexto de creciente institucionalización y de humanización que el orden internacional contemporáneo parece venir experimentando desde hace años ${ }^{15}$, de forma evidente, al menos, en dos sectores del Derecho internacional: el Derecho internacional humanitario y el Derecho Internacional de los derechos humanos, se enmarcaría el reconocimiento de la legitimación activa y pasiva de la persona humana ante órganos internacionales de carácter jurisdiccional en relación con las disposiciones contenidas en los sectores normativos del Derecho internacional de los derechos humanos y del Derecho internacional humanitario. Este proceso de humanización del Derecho internacional no habría avanzado, sin embargo, a un ritmo idéntico en ambos sectores normativos ${ }^{16}$, siendo posible comprobar cómo el Derecho internacional humanitario ha enfatizado más la legitimación pasiva de los individuos, codificando la responsabilidad penal individual frente a la Comunidad Internacional en su conjunto.

Una posible explicación de carácter histórico la ofrecía Von Der Heydte cuando examinaba los Tribunales Militares Internacionales de Nuremberg y Tokio como un desarrollo del proceso de proscripción de la guerra iniciado en 1928 con el Pacto Briand-Kellog. En virtud de dicho Pacto, se preveía una sanción para el Estado que decidiera recurrir a la guerra como instrumento de su política nacional: el ser declarado fuera de la ley. Dicha sanción fue completada más tarde en 1932 por la doctrina Stimson, promovida por el Secretario de Estado norteamericano a quien debe su nombre y según la cual, los Estados Unidos no reconocerían títulos o derechos pretendidos, adquiridos en violación del Pacto Briand-Kellog, del Pacto de la Sociedad de Naciones o de otros tratados. Como recuerda Von Der Heydte, se estimó necesario que ambas tentativas desesperadas por hacer valer el Derecho de Gentes contra el poder absoluto de los Estados totalitarios para los cuales todo derecho no era más que un instrumento de poder, fueran completadas con una tercera sanción.

Así, en virtud del Acta de Londres de 8 de agosto de 1945, con el castigo a los grandes criminales de guerra, la tercera sanción consistiría en una responsabilidad personal de los órganos estatales al lado de la responsabilidad general

${ }^{15}$ Carrillo Salcedo, J. A., Soberanía del Estado y Derechos Humanos en Derecho Internacional Contemporáneo, Tecnos. Madrid, 2001, pp. 13-14.

${ }^{16}$ Rodríguez Carrión, A., Lecciones de Derecho Internacional Público, 6 a ed., Tecnos, Madrid, 2006, p. 143. 
del Estado ${ }^{17}$. De este modo, la mayor accesibilidad de los individuos en su dimensión pasiva ante jurisdicciones internacionales se explicaría porque más que reconocer una subjetividad internacional del individuo, en los Tribunales Internacionales Penales (los referidos de Nuremberg y Tokio) se reconocía internacionalmente la legitimación pasiva del individuo en tanto en cuanto que éste estaría representando al Estado cuya sanción se pretendía ${ }^{18}$. Esta explicación no encuentra, sin embargo, apoyo en el fallido proyecto de Gustave Moynier de creación de una institución internacional encargada del juzgamiento y castigo de los responsables individuales de violaciones de la Convención de Ginebra de 22 de agosto de 1864, relativa a la mejora de la suerte de los soldados heridos y enfermos en campaña ${ }^{19}$. En dicho proyecto de Tribunal Internacional Penal los individuos no representaban al Estado por lo que, como reconocía el propio Moynier, «éstos nunca serían directamente encausados» ${ }^{20}$. No se pretendía, así pues, añadir una sanción al Estado que hubiera permitido, con ocasión de un conflicto armado, la violación de la Convención de Ginebra de 1864 sino castigar a individuos concretos por la violación de ciertas normas internacionales del Derecho de la guerra consideradas de especial trascendencia. Una idea civilizadora y progresista para una sociedad internacional en la que los Estados eran considerados como los únicos sujetos del Derecho internacional ${ }^{21}$ y por tanto, los únicos responsables y legitimados para exigir responsabilidad a otros Estados.

${ }^{17}$ Von Der Heydte, F. A., «L'individu et les Tribunaux Internationaux», Recueil des Cours de L'Académie de Droit International de La Haye, Vol. 107, 1962, pp. 349-350.

${ }^{18}$ Ibídem, p. 351.

${ }^{19}$ El proyecto tras ser presentado ante el Comité Internacional de la Cruz Roja en Ginebra el 3 de enero de 1872 apareció publicado en el que era el correo oficial de esta institución (el Bulletin International des Societés de Secours aux Militaires Blessés, no 11, abril de 1872, pp. 12-131). No se trataba de un autentico tribunal internacional penal, permanente y pre constituido sino de un tribunal arbitral que habría de constituirse para cada conflicto. Sobre el tema véase: Petit Gabriel, E. W., «La propuesta del Tribunal Penal Internacional de Gustave Moynier, un proyecto antiguo recientemente rescatado (18721998)», Carrillo Salcedo, J. A., (Coord.), La criminalización de la barbarie: La Corte Penal Internacional, Consejo General del Poder Judicial, Madrid, 2000, pp. 29-87. Igualmente: MAY, K. Ch., «The First Proposal for a Permanent International Criminal Court», International Review of the Red Cross, $\mathrm{n}^{\circ} 322$, marzo 1998, pp. 57-74.

${ }^{20}$ MoYNIER, G., «Note sur la création d'une institution judiciare internationale propre à prévenir et à réprimer les infraccions à la Convention de Genève», Bulletin International des Sociétés de Secours aux Militaires Blesses, n 11, 1872, p. 126 (Tomado del trabajo citado: «La propuesta del Tribunal Penal Internacional de Gustave Moynier, un proyecto antiguo recientemente rescatado (1872-1998)».

${ }^{21}$ Como reconoció la Corte Permanente de Justicia Internacional en 1927 en el caso el Lotus: «El Derecho Internacional rige las relaciones entre Estados independientes. Las reglas de Derecho que vinculan a los estados proceden, pues, de la voluntad de éstos, voluntad manifestada en convenciones o en usos que se aceptan generalmente como consagradores de principios de Derecho y establecidos con el fin de regular la coexistencia de estas comunidades independientes y con el objeto de la prosecución de fines comunes.» CPJI série $A \mathrm{n}^{\mathrm{o}} 10$, sentencia $\mathrm{n}^{\circ}$ 9, p. 18. 
El interés de la Comunidad Internacional respecto de la previsión de la justicia universal como vía para hacer efectiva la responsabilidad internacional de los individuos por la comisión de violaciones de derechos humanos no habría sido similar al mostrado a la hora de su enunciado pues, como escribe Esperanza Orihuela Calatayud, «siempre es más fácil enunciar derechos que establecer mecanismos eficaces de protección. $\rangle^{22}$

A pesar de la regulación relativamente reciente de los derechos de las víctimas, los resultados en el plano internacional son evidentes. Diversas disposiciones contenidas en instrumentos internacionales reconocen el derecho a un recurso efectivo para las víctimas de las violaciones de las normas del Derecho Internacional Humanitario. Así, deben señalarse el artículo 3 de la Convención de La Haya de 18 de octubre de 1907, relativa a las leyes y costumbres de la guerra terrestre (Convención $n^{\circ}$ IV de 1907). Asimismo, el artículo 91 del Protocolo Adicional de los Convenio de Ginebra de 1949, relativo a la protección de las víctimas de los conflictos armados internacionales (Protocolo I).

\subsection{Los antecedentes recientes}

Los Tribunales híbridos vieron la luz desde los años 90 del pasado Siglo $\mathrm{XX}$ en el marco del esfuerzo de justicia penal internacional. Se trataba de un conjunto muy heterogéneo de cuatro entidades: los mecanismos jurisdiccionales creados para Timor Oriental, Kosovo, Sierra Leona y Camboya ${ }^{23}$. Se les denominaba internacionalizados o híbridos porque tanto el aparato institucional como el derecho aplicable consistía en una mezcla de lo internacional y de lo interno. De este modo, los jueces extranjeros se sentaban junto con los internos y juzgaban los casos aplicando Derecho interno reformado de acuerdo con estándares internacionales ${ }^{24}$. Naciones Unidas jugó un decisivo papel en su establecimiento. Así, suscribiendo un tratado con Sierra Leona y Camboya, tratándose del Tribunal Especial de Sierra Leona y de las Salas Especiales de Camboya ${ }^{25}$, respectivamente. Igualmente, los Paneles de jueces

${ }^{22}$ Orihuela Calatayud, E., «Justicia universal y derechos humanos», Cursos de Derechos Humanos de Donostia-San Sebastián. Universidad del País Vasco, San Sebastián, 2002, p. 116.

${ }^{23}$ Romano, C. P. R., Boutruche, T., « Les Tribunaux Penales Internationalisés: etat d'une Justice hybride », Revue Général de Droit International Public, 2003-1, p. 110. En la página del Project on International Courts and Tribunals www.pict-pcti.org/courts/hybrid.html aparece una descripción y documentación referida a cada uno de estos Tribunales Penales Internacionalizados.

${ }^{24}$ Dickinson, L., «The Promise of Hybrid Tribunals», American Journal of International Law, Vol. 97, n 2, 2003, p. 295.

${ }^{25}$ (La base jurídica del Tribunal Especial para Sierra Leona es un acuerdo entre la ONU y este Estado de 16 de enero de 2002: Agreement between the United Nations and the Government of Sierra Leona on the Establishmnet of a Special Court for Sierra Leona, que ha sido ratificado por el Parlamento de Sierra Leona. Tratándose de Camboya, tras la 
internacionales en los tribunales de Kosovo y los Paneles Penales del Tribunal de Distrito de Dili, encuentran su base jurídica en decisiones de las Administraciones Transitorias de Naciones Unidas en estos países, la MINUK y la MINUTO, respectivamente.

Este modelo híbrido se desarrolló particularmente en situaciones posteriores a un conflicto cuando no existe una posibilidad de acudir a un Tribunal internacional (como en Timor Oriental o Sierra Leona porque la competencia ratione materiae de los Tribunales $A d$ hoc o la ratione temporis de la Corte Penal Internacional no lo permitían); asimismo, cuando un tribunal internacional existe, como en Kosovo, pero no puede ocuparse del ingente número de casos. Una cuestión clave es el decisivo papel jugado por la Organización de Naciones Unidas en el proceso de establecimiento de estos tribunales: éstos resultan bien de un acto normativo de esta Organización bien de un acuerdo celebrado entre el Estado concernido y la Organización. Así, por lo que hace a Sierra Leona, y a Camboya, las cortes internacionalizadas encuentran su origen en un tratado libremente negociado y concluido entre el gobierno concernido y la Organización de Naciones Unidas. Por el contrario, tratándose de los Paneles de jueces internacionales en los Tribunales de Kosovo según la «Regulation 64» y los Paneles Penales (Crimes Panels) del Tribunal de Distrito de Dili, la base jurídica reside en las competencias en materia de justicia de las Administraciones transitorias de Naciones Unidas en Kosovo (MINUK) y Timor Oriental (MINUTO), respectivamente.

\subsection{Significado y alcance de la justicia penal internacional en un proceso de reconstrucción internacional de un Estado constitucional}

La relación entre el principio de la justicia penal y el principio de la salvaguardia de la paz, en especial, tras un conflicto armado, es bien conocida. A los efectos de esta contribución me limitaré a señalar evidencias de esta relación en el Estatuto de la Corte Penal Internacional. En su preámbulo, el principio de la justicia penal internacional está recogido en los párrafos 4 y 11:

«Afirmando que los crímenes más graves de trascendencia para la comunidad internacional en su conjunto no deben quedar sin castigo y que, a tal fin, hay que adoptar medidas en el plano nacional e intensificar la cooperación internacional para asegurar que sean efectivamente sometidos a la acción de la justicia.»

adopción por el Parlamento Camboyano de una ley por la que se crean Salas especiales, siguió un acuerdo de 18 de marzo de 2003 entre las Naciones Unidas y el Real Gobierno de Camboya para el procesamiento por los crímenes cometidos durante el período de la Kampuchea Democrática, recogido en la Resolución A/RES57/228B, de la Asamblea General, de 13 de mayo de 2003. En la página de la Universidad de Yale www.yale.edu/cgp/news.html puede consultarse relevante información sobre el Tribunal de Camboya. 
«Decididos a garantizar que la justicia internacional sea respetada y puesta en práctica en forma duradera,»

El principio de la justicia se encuentra influenciado por otro principio expresado con igual fuerza en el mismo preámbulo del Estatuto: la salvaguarda de la paz internacional. Véanse los párrafos 3 y 7 y nótese la referencia a los propósitos y principios de la Carta de Naciones Unidas y, en especial a los apartados 4 y 7 del artículo 2 de la misma:

«Reconociendo que esos graves crímenes constituyen una amenaza para la paz, la seguridad y el bienestar de la humanidad,»

«Reafirmando los Propósitos y Principios de la Carta de las Naciones Unidas y, en particular, que los Estados se abstendrán de recurrir a la amenaza o al uso de la fuerza contra la integridad territorial o la independencia política de cualquier Estado o en cualquier otra forma incompatible con los propósitos de las Naciones Unidas.»

Como resultado de esta interacción entre ambos principios la idea de justicia aquí evocada, es la que alude a una categoría de derechos humanos y de obligaciones de Derecho internacional humanitario que la comunidad internacional no puede dejar violar impunemente -en especial con ocasión de un conflicto armado- porque suponen un grave ataque al orden público internacional y, en todo caso, impiden una paz duradera entre víctimas y verdugos. Desde esta perspectiva se entiende la notable labor realizada por Naciones Unidas a través de la creación de Tribunales Penales Internacionalizados o híbridos.

A la luz de estos desarrollos en Derecho internacional, en especial, gracias a la labor de Naciones Unidas parece evidente que ha emergido una obligación: el principio de equidad para las víctimas de graves crímenes contra el Derecho internacional que enraíza con las transformaciones experimentadas en numerosos ordenamientos internos estatales a favor del reconocimiento de los derechos de las víctimas de delitos comunes. El principio de equidad para las víctimas de graves crímenes contra el Derecho internacional incluye dos grupos de derechos: por un lado el derecho a la justicia (acceso a un tribunal y a tener reconocida una cierta participación procesal en el mismo). Por otro lado, el derecho a una reparación (responsabilidad civil ex delicto de autor de dicho crimen y compensación a cargo del Estado del cual sea nacional o bajo cuya autoridad actuó el autor de dicho crimen).

La relación entre un Tribunal Penal internacional con competencia para juzgar a los responsables de graves crímenes contra los derechos humanos y las normas elementales del Derecho Internacional humanitario, con el día a día de la necesaria convivencia entre los que han siso víctima y verdugo, como medio de lograr la reconstrucción del Estado y una cierta vuelta a la «normalidad», es una de esas cuestiones para las que no es fácil encontrar respuesta. Si el fin de la impunidad es un paso previo, inevitable, para cualquier tipo de 
reconciliación nacional, la justicia no puede ser selectiva, en función de un fin -por loable que sea- de la reconciliación nacional y de la consolidación de la paz en una sociedad post conflicto. Ahora bien, ¿es esto posible siempre? La experiencia reciente de Ruanda es ilustrativa al respecto.

La Resolución 955 (1994) del Consejo de Seguridad de Naciones Unidas, por la que se instituyó el Tribunal Penal Internacional ad hoc para Ruanda, enunciaba en el párrafo séptimo de su preámbulo tanto el principio de la justicia como el de la paz:

«Convencidos de que, en las circunstancias particulares de Ruanda, el enjuiciamiento de los responsables de graves violaciones del derecho internacional humanitario permitiría alcanzar este objetivo y contribuiría al proceso de reconciliación nacional y al restablecimiento y el mantenimiento de la paz» (la cursiva es añadida).

El principio de la justicia penal -representado por el deseo de castigar a los responsables de los crímenes enunciados en el Estatuto de este Tribunalse recoge en los párrafos sexto y octavo de la Resolución 955:

«Decididos a poner fin a esos crímenes y a tomar medidas eficaces para hacer comparecer ante la justicia a los responsables».

«Estimando que la creación de un Tribunal Internacional para el enjuiciamiento de los presuntos responsables del genocidio y demás violaciones antes mencionadas del derecho internacional humanitario contribuirá a que se ponga fin a esas violaciones y a que sean reparadas efectivamente».

Ahora bien, ¿hasta qué punto son compatibles ambos principios? ¿Pueden satisfacerse ambos sin que sea necesario sacrificar uno en beneficio del otro? Llegado el caso, ¿cuál de los dos prevalecerá? Y ¿a qué coste? En el caso del genocidio ruandés, la tensión que late entre ambos principios explica, por ejemplo, la delimitación temporal de la competencia del Tribunal a los hechos cometidos durante 1994: reflejaría el deseo de la Comunidad Internacional de lograr un compromiso entre la propuesta de remontarse a un período anterior al 1 de enero de 1994 (con lo que se inculparían a los líderes hutus que organizaron y planificaron el genocidio), y la propuesta de extenderla a una fecha posterior al 31 de diciembre de 1994 (con lo que se podría inculpar a los tutsis que cometieron actos similares a los imputados a los hutus durante la confrontación y una vez tomado el control del gobierno de Ruanda. ${ }^{26}$ En este sentido, se afirmó al poco de la creación del TPIR, que su verdadera finalidad fue el restablecimiento del Estado ruandés, a través de la reconciliación nacional lograda sobre la base de un castigo a los culpables que pusiera

${ }^{26}$ Shraga, D., ZaCKLIN, R., «The International Criminal Tribunal for Rwanda», European Journal of International Law, 1996, pp. 506-507. 
fin a una cultura de impunidad. ${ }^{27}$ La sociedad ruandesa se encontró -como mutatis mutandis sucedió con las sociedades argentina y sudafricana-dividida entre la necesidad de arrojar luz sobre su pasado y la necesidad de actuar a favor de la reconciliación nacional. La solución que se dio en el caso de Ruanda, siguiendo al profesor Meron fue aceptar que lo importante «no es cuántos casos de atrocidades puedan tratar los Tribunales Internacionales sino el profundo mensaje que transmite su misma existencia, propiciando así el desarrollo del derecho mediante sus estatutos, sus normas de procedimiento y de prueba así como mediante la práctica. ${ }^{28}$ En otros términos, no importa tanto el que todos o los principales responsables criminales paguen por sus actos, como que la población -que busca venganza-y otros líderes africanos -que pueden verse tentados en el futuro de cometer actos similares a los perseguibles por el TPIR-percibieran el fin de la «cultura de la impunidad» a través de la identificación individual de los genocidas y de los autores de crímenes de guerra y de lesa humanidad.

Otro ejemplo más reciente de la práctica internacional incide en la misma dirección. Para entender el significado de la respuesta de la comunidad internacional en relación con la represión y castigo de los autores de crímenes contra el Derecho Internacional en Sudán, hay que hacer necesariamente una referencia al Informe de 25 de enero de 2005, de la Comisión Internacional de Investigación nombrada por el entonces Secretario General, Kofi Annan, para evaluar la situación en Darfour, de conformidad con la Resolución del Consejo de Seguridad 1564, de 18 de septiembre de 2004. En el mismo se afirmaba la necesidad de hacer justicia en Darfour:

«La magnitud y grave naturaleza de los crímenes cometidos contra la población civil en Darfour, tanto por las tropas del Gobierno como por los Janjaweed, y por los rebeldes, requiere una inmediata acción por la comunidad internacional para poner fin a estas atrocidades. Los autores de estos crímenes deben ser traídos a la justicia. Al mismo tiempo, medidas que traigan socorro y alivio a las víctimas deben ser puesta en marcha para completar el proceso de responsabilidad penal» ${ }^{29}$.

${ }^{27}$ Erasmus, G., Fourie, N., «The International Criminal Tribunal for Rwanda: Are All Issues Addressed? How Does It Compare to South Africa's Truth and Reconciliation Commission?», International Review of the Red Cross, $\mathrm{n}^{\circ} 37,1997, \mathrm{p} .752$.

${ }^{28}$ Meron, T., «The International Criminalization of Internal Atrocities», American Journal of International Law, 1995, p. 555.

${ }^{29}$ NACIONES UNIDAS, Informe de 25 de enero de la Comisión Internacional de Investigación nombrada por el Secretario General, Kofi Annan, para evaluar la situación en Darfour, de conformidad con la Resolución del Consejo de Seguridad 1564, de 18 de septiembre de 2004 (en adelante, «Informe de la Comisión Internacional en Darfour»), parágrafo 565 . 
Es de destacar que no sólo el Consejo de Seguridad de Naciones Unidas en sus Resoluciones de 1556 y 1564 enfatizó la urgente necesidad de justicia, sino que también, todas las partes en conflicto en Darfour insistieron en el principio de responsabilidad ${ }^{30}$. En este sentido la Comisión expresó la opinión que dos medidas debían ser tomadas por el Consejo de Seguridad para asegurar que se hiciera justicia respecto de los crímenes cometidos en Darfour, teniendo en mente que cualquier mecanismo de justicia debe adherirse a determinados principios reconocidos: debe ser imparcial, independiente y justo. Con respecto al mecanismo de responsabilidad por vía judicial, la Comisión recomendó que el Consejo de Seguridad trasladase la situación de Darfour a la Corte Penal Internacional ${ }^{31}$. La otra medida contemplada fue llevar compensación a las víctimas de tan graves violaciones de los derechos humanos, la mayor parte de los cuales eran constitutivos de crímenes contra el Derecho internacional. Se propuso, así pues, que una Comisión de compensación fuera establecida por el Consejo de Seguridad ${ }^{32}$.

En relación con la primera de las medidas propuestas, que el Consejo de Seguridad sometiera la situación de Darfour a la Corte Penal Internacional, se pensaba que ante un consistente patrón de violaciones de derechos humanos a gran escala, no sólo los Estados individualmente sino también la comunidad internacional de Estados en su conjunto a través de su órgano político más importante debería reaccionar enérgicamente ${ }^{33}$. Más aún, la Comisión presidida por el Profesor Cassese señalaba que el Consejo de Seguridad había enfatizado en sus resoluciones 1556 y 1564 la necesidad de poner fin a la impunidad en Darfour, para que el fin de dicha impunidad pueda contribuir a restablecer la seguridad en la región y con ello, permitiendo que los cientos de miles de personas desplazadas internas pudieran regresar a sus hogares o a otros lugares de su elección ${ }^{34}$. Ante la sugerencia de algunos Estados de establecer una Comisión de Reconciliación Nacional en Sudán semejante a la que se creó en Sudáfrica, la Comisión Internacional de Investigación presidida por el Profesor Cassese consideró que si bien una tal Comisión podía jugar un importante papel en asegurar la justicia y la responsabilidad por vía judicial $^{35}$, se mostró, sin embargo, reacio a su creación señalando que:

${ }^{30}$ Parágrafo 566 del Informe de la Comisión Internacional en Darfour.

${ }^{31}$ Parágrafo 569 del Informe de la Comisión Internacional en Darfour.

${ }^{32}$ Parágrafo 570 del Informe de la Comisión Internacional en Darfour.

${ }^{33}$ Ibidem, parágrafo 589.

${ }^{34}$ Ibidem.

${ }^{35}$ Observando que: «Los Tribunales penales, por sí solos, pueden no ser adecuados para revelar el amplio espectro de crímenes que ocurrieron durante un período de represión, en parte porque sólo pueden condenar sobre la base de la prueba más allá de una duda razonable. En situaciones de crímenes en masa, tales como los que sucedieron en Darfour, un relativamente limitado número de persecuciones, no importa cuán exitosas sean, puede no satisfacer completamente las expectaciones de las víctimas de que se conozca su sufrimiento. Lo que es importante, en Sudán, es una completa revelación del ámbito completo 
«El saber si la Comisión de Verdad y Reconciliación sería apropiada para Sudán y en qué medida debería ser establecida, es un asunto que sólo la gente de Sudán debería decidir a través de un proceso auténticamente participativo. Estas decisiones, teóricamente, sucederían: i) una vez que el conflicto estuviera concluido y la paz restablecida; ii) como una medida complementaria a la persecución penal, que en cambio debería ser establecida tan pronto como sea posible, incluso si el conflicto está aún pendiente, con vista a tener un efecto disuasorio, esto es, parando más violencia; y iii) sobre la base de una informada discusión entre las más amplias capas de la sociedad sudanesa, que tome en consideración la experiencia internacional y, sobre estas bases, valore la probable contribución de la Comisión de Verdad y Reconciliación a Sudán. Reciente experiencia internacional indica que la Comisión de Verdad y Reconciliación es probable que tenga credibilidad e impacto cuando sus mandatos y composición están determinados sobre la base de un amplio proceso consultivo, incluyendo la sociedad civil y los grupos de víctimas. Unas Comisiones de Verdad y Reconciliación establecidas con el propósito de sustituir a la Justicia o producir una verdad distorsionada, debería ser evitada.» ${ }^{36}$

La Resolución 1593 del Consejo de Seguridad, de 31 de marzo de 2005, aprobada por 11 votos a favor, ninguno en contra y cuatro abstenciones (Argelia, Brasil, China y Estados Unidos), supuso la primera vez que el Consejo de Seguridad remitía un caso a la Corte Penal Internacional (Ver artículo 13 del Estatuto) alegando que «la situación en Sudán sigue constituyendo una amenaza a la paz y la seguridad internacionales». El 6 de junio de 2005, el Fiscal de la Corte Penal Internacional comenzó la investigación de los crímenes cometidos en Darfour. Sudán firmó el Estatuto de Roma el 8 de septiembre de 2000 pero no habiéndolo ratificado, no es Estado parte en el mismo ni acepta su jurisdicción. Hasta el momento, la Corte Penal Internacional ha emitido tres órdenes de arresto y una orden de comparecencia (la primera en su historia), estando abiertos tres $\operatorname{casos}^{37}$.

\section{LOS VECTORES DE UN NUEVO PARADIGMA INTERNACIONAL DE ESTADO CONSTITUCIONAL}

Bajo la premisa de que entre los Estados constitucionales liberales no se producen situaciones que puedan derivan en un conflicto armado, se asume, como preferible, un ambiente pacífico para el crecimiento y el fortalecimiento

de criminalidad cometida.» Parágrafo 617 del Informe de la Comisión Internacional en Darfour.

${ }^{36}$ Parágrafo 621 del Informe de la Comisión Internacional en Darfour.

${ }^{37}$ Caso el Fiscal contra Ahmad Muhammad Harun y Ali Muhammad Ali Abd-Al-Rahman, Caso el Fiscal contra Omar Hassan Ahmad Al-Bashir, y Caso el Fiscal contra Bahr Idriss Abu Garda. 
de un mercado a escala mundial. De este modo, los Estados constitucionales no liberales son invitados, de un modo más o menos vehemente, a unirse a la Comunidad de Estados Liberales, caracterizada por una lista de atributos que incluyen la paz, un gobierno liberal democrático, una densa red de transacciones transnacionales por parte de actores sociales y económicos, «múltiples canales» de comunicación y acción los cuales, más que formalmente interestatales, serían transgubernamentales, así como una difuminación de la distinción entre asuntos internos e internacionales ${ }^{38}$.

Los defensores de la vieja idea de la «paz perpetua» de Emmanuel Kant se olvidan, sin embargo, de señalar los límites de la democracia a la hora de crear un mundo más pacífico: por ejemplo, los Estados constitucionales democráticos no tienen ninguna dificultad para ir a la guerra contra otros Estados que ellos consideren no democráticos o la naturaleza violenta de algunas nuevas democracias, como la Federación Rusa, con un incremento de conflictos internos desde su adscripción al régimen democrático ${ }^{39}$. Ajenos a esta Comunidad de Estados constitucionales liberales estarían los Estados «bárbaros», caracterizados por padecer una situación de persistente violación de los derechos humanos y por reflejar formas de gobierno que no se corresponden con un modelo de constitución democrática. Se polariza así la sociedad internacional entre «nosotros y ellos» ${ }^{40}$, si bien esa Comunidad de Estados constitucionales liberales no tiene sus puertas cerradas a estos «Estados bárbaros», quienes, por el contrario, son incesantemente invitados a integrarse a esta comunidad liberal, a través de la aceptación de las condiciones unilateralmente impuestas desde la misma, una de las cuales es la asunción -bajo el paraguas de una constitución consensuada a nivel nacional- de la democracia formal, esto es, la celebración de elección libres, periódicas y bajo supervisión independiente.

Con estas condiciones, numerosos países deciden incorporarse a esta comunidad liberal como requisito necesario para entrar en el circuito económico y comercial mundial (recepción de inversiones y de ayudas al desarrollo, etc.). En la práctica, sin embargo, las elecciones no proporcionan, por sí solas, las bases para un Estado constitucional efectivamente democrático ${ }^{41}$. Es por ello que puede sostenerse la necesidad de contar con un concepto universal de Estado constitucional, especialmente válido para reconstruir sociedades postconflicto. Este concepto desde el paradigma del Derecho internacional -en especial, a la luz de la reciente práctica internacional que enfatiza la soberanía responsable frente a la comisión de graves violaciones contra los derechos

${ }^{38}$ SLAUGHTER, A.-M., «International Law in a World of Liberal States», European Journal of International Law, Vol. 6, $\mathrm{n}^{\circ}$ 4, 1995, vol. 6, p. 510.

${ }^{39}$ BuRCHILL, R., «The Developing International Law of Democracy», The Modern Law Review, Vol. 64, 2001, p. 129.

${ }^{40}$ Ibidem, p. 130.

${ }^{41}$ Ibidem, p. 125. 
humanos y las normas de Derecho Internacional Humanitario- ha de ser un concepto identificable a partir de tres vectores: la legitimidad de los gobernantes (legitimacy), la intangibilidad de los derechos humanos de los gobernados (intangibility of human rights) y el principio de la rendición de cuentas por la violación de los mismos(accountablity) ${ }^{42}$.

\subsection{La legitimidad de los gobernantes (legitimacy)}

La legitimidad desde el Derecho internacional no equivaldría a la asunción uniforme de principios políticos, económicos, sociales, culturales o religiosos por parte de los distintos gobiernos del mundo. Por el contrario bastaría que todos ellos expresaran su adhesión a los propósitos y principios enunciados en la Carta de Naciones Unidas, reflejo de unos valores que aluden a la humanidad como detentadora de los mismos ${ }^{43}$, y que se asuma la vía del consenso como la mejor forma de ocuparse de las cuestiones que interesan a todos en la medida en que esos valores representan un acuerdo básico sobre las reglas del juego válidas para todos los Estados por encima de sus diferencias.

En efecto, analizados en perspectiva histórica durante la segunda mitad del pasado siglo, los valores proclamados en la Carta de San Francisco en 1945 se han beneficiado durante todos estos años de una indiscutida legitimidad, que debe ser destacada en nuestros días, por varias razones. En primer lugar, al ser valores incluyentes, esto es, valores que hacían referencia al conjunto de Estados, no sólo a los vencedores de la Segunda Guerra Mundial. En consecuencia, eran valores que podían ser aceptados y compartidos por los nuevos Estados que venían a integrarse en la Comunidad internacional al surgir del proceso de descolonización. En segundo lugar, por encima de ser valores de la Comunidad internacional son valores, como se ha dicho, que evocan a la idea de humanidad, concepto éste atemporal e interespacial que se refiere a los que ya están pero, también, a los que han de venir ${ }^{44}$. Así, los diversos cambios experimentados en la sociedad internacional durante la segunda mitad del siglo XX (la descolonización, el final de la guerra fría, la caída del muro de Berlín, etc.) no alteraron sustancialmente este sistema de valores finales (lo que se quería conseguir) e instrumentales (por qué vías),

${ }^{42}$ García SAn JosÉ, D., «El Concepto de Democracia en Derecho Internacional», Revista Jurídica de la Universidad Autónoma de Madrid, nº 14, 2006, pp. 65-86.

${ }^{43}$ Véase el preámbulo de la Carta de San Francisco: «Nosotros, los pueblos de las Naciones Unidas». Idea ésta reiterada con posterioridad, por ejemplo en la Declaración sobre los principios de Derecho Internacional referente a las relaciones de amistad y a la cooperación entre los Estados de conformidad con la Carta de las Naciones Unidas (Resolución 2625.XXV, aprobada por la Asamblea General de naciones Unidas el 24 de octubre de 1970) o en la Declaración con motivo del cincuentenario de las Naciones Unidas (Resolución 50/6, aprobada por la Asamblea General el 24 de octubre de 1995).

${ }^{44}$ DupuY, R.-J., L'avenir du droit international dans un monde multiculturel, Martinus Nijhoff, La Haye, 1984, p. 459. 
sino que los complementaron con nuevos valores finales (la justicia, la paz, el desarrollo) e instrumentales (a través de la cooperación para el desarrollo de los pueblos, del respeto de la dignidad del ser humano a través del reconocimiento y protección internacional de los derechos humanos, o mediante la aceptación del principio democrático como legitimador de un gobierno dispuesto a asumir sus compromisos internacionales).

Se entiende a la luz de estas consideraciones que en su informe El Estado de Derecho y la justicia de transición en las sociedades que sufren o han sufrido conflictos, el Secretario General de Naciones Unidas haya defendido una aproximación multilateral e institucionalizada a las situaciones posteriores a un conflicto (a menudo de carácter interno) en apoyo de la justicia y del Estado de derecho porque:

«Las normas y los principios de las Naciones Unidas han sido formulados y aprobados por países del todo el mundo y acogidos por toda la variedad de sistemas jurídicos de los Estados Miembros, ya estén basados en el Common Law, la tradición romanista, el derecho islámico $\mathrm{u}$ otras tradiciones jurídicas. Esas normas y principios proporcionan por sí mismos una legitimidad que no puede reconocerse a los modelos nacionales exportados que tantas veces reflejan los intereses individuales o las experiencias de donantes o de quienes aportan asistencia más que los intereses superiores o las necesidades de desarrollo jurídico de los países receptores..$\rangle^{45}$

\subsection{La intangibilidad de los derechos humanos fundamentales (intangi- bility of human rights)}

En el sentido referido por el profesor CARRILLO SALCEDO cuando afirma que:

«La prohibición de los crímenes contra la humanidad, de la privación arbitraria de la vida, de la tortura, junto con la afirmación del carácter intrasgredible de los principios esenciales del Derecho Internacional Humanitario, son ejemplos de la progresiva consolidación en Derecho internacional público positivo de una especie de orden público internacional, esto es, de principios y normas de ius cogens internacional, cuyo fundamento último se encuentra en la idea de comunidad internacional y en la convicción de que existen en ella unos principios y normas por encima de la voluntad de los Estados. $\rangle^{46}(\mathrm{La}$ cursiva es original)

${ }^{45}$ Naciones Unidas, Informe del Secretario General de Naciones Unidas de 3 de agosto de 2004, Doc. S/2004/16, parágrafo 10.

${ }^{46}$ Carrillo Salcedo, J. A., Droit International et Souveraineté des États. Cours General de Droit International Public, Recueil des Cours de l'Académie de Droit International de La Haye, 1996, tome 257, pp. 64-67 y 221. 
Se trataría de unas consideraciones elementales de humanidad ${ }^{47}$ reflejadas en la cláusula Martens común a los principales Convenios de Derecho Humanitario, incluyendo las Convenciones de la Haya de 1899 y 1907, relativas a las leyes y usos de la guerra. Ahora bien, ¿es posible afirmar la existencia de principios intrasgredibles en materia de Derecho internacional de protección de derechos humanos en conexión con las exigencias del principio democrático? Pienso que sí pues si bien la democracia no implica los derechos humanos, pudiendo incluso entrar en contradicción con ellos, los derechos humanos presuponen, en cambio, la democracia que no puede realizarse plenamente sin éstos. A mayor abundamiento, la existencia de principios intrasgredibles del Derecho Internacional humanitario ha sido reconocida por la Corte Internacional de Justicia en su dictamen de 8 de julio de 1996 en el asunto de la amenaza y empleo de armas nucleares:

- $\quad$ el principio de distinción entre combatientes y no combatientes;

- la prohibición de usar armas de efecto indiscriminatorio;

- la prohibición de causar sufrimiento innecesario a los combatientes;

- $\quad$ el hecho de que no es ilimitado el derecho de los Estados a elegir los medios de hacer la guerra ${ }^{48}$.

\subsection{La rendición internacional de cuentas (accountability)}

La clave para entender este tercer y último principio vertebrador del concepto de Estado constitucional postulado desde el Derecho internacional a partir de una relectura de la soberanía, la aportó el Secretario General de Naciones Unidas en su informe de 21 de marzo de 2005 titulado Un concepto más amplio de libertad: desarrollo, seguridad y derechos humanos para todos, cuando señaló que:

«Los Estados soberanos son los componentes básicos e indispensables del sistema internacional. A ellos les corresponde garantizar los derechos de sus ciudadanos, protegerlos de la delincuencia, la violencia y la agresión y crear el marco de libertad al amparo de la ley que permita a las personas prosperar y a las sociedades desarrollarse... Sin embargo, esta tarea no puede hacerla sólo los Estados. Necesitamos una sociedad civil activa y un sector privado dinámico. Ambos ocupan una porción cada vez más amplia e importante que antes era coto exclusivo de los Estados... También necesitamos, a nivel regional y mundial, unas instituciones intergubernamentales ágiles y eficaces que puedan movilizar y coordinar la acción colectiva. Las Naciones Unidas, por ser el único órgano universal del mundo dedicado a atender cuestiones de seguridad, desarrollo y derechos humanos, tiene una responsabilidad especial.» ${ }^{49}$

${ }^{47}$ Carrillo Salcedo, J. A., Soberanía de los Estados y Derechos Humanos en Derecho Internacional Contemporáneo, op. cit., p. 153.

${ }^{48}$ ICJ, Reports, 1996, parágrafo 78.

${ }^{49}$ Doc. A/59/2005, parágrafos 19 a 21. 
A partir de la asunción del principio de rendición de cuentas en el Derecho internacional se entiende la tendencia evidente en los últimos años a reforzar el principio de la legitimidad internacional ${ }^{50}$ en el reconocimiento de la existencia de nuevos Estados (y de Gobiernos): el contar con un régimen democrático, el respeto de los derechos humanos y del principio de la primacía del Derecho (the rule of Law) poniendo el acento en la responsabilidad inherente a la soberanía ${ }^{51}$. De esta forma, el principio de la igualdad soberana sigue siendo una piedra angular del Derecho internacional pos contemporáneo pero se halla permeabilizado por el principio de legitimidad internacional conforme a unos valores universales, uno de los cuales sería el principio democrático. En este sentido, la Comisión internacional nombrada por el entonces Secretario General de Naciones Unidas para investigar los sucesos en Darfur y que estuvo presidida por el profesor Antonio Cassese, recordaba respecto de Sudán, en su informe de 25 de enero de 2005, que:

«Sudán es un Estado soberano y su integridad territorial deber ser respetada. Aun cuando esta Comisión reconoce que Sudán tiene derecho a tomar medidas para mantener o restablecer su autoridad y defender su integridad territorial, la soberanía conlleva responsabilidad. Sudán es requerido no sólo a respetar el Derecho internacional sino también a asegurar su respeto. Es lamentable que el Gobierno de Sudán haya fallado en proteger los derechos humanos de su propia gente. Las medidas tomadas para contrarrestar la insurgencia en Darfur han sido una flagrante violación del Derecho internacional. La Comunidad internacional debe, así pues, actuar inmediatamente y tomar medidas para asegurar la responsabilidad por vía judicial. Aquellos miembros de grupos rebeldes que hayan cometido graves violaciones de derechos humanos y del Derecho humanitario también debe serles exigida responsabilidad. $\rangle^{52}$

Esos tres ejes vectores (legitimacy, intangibility y accountability) de un concepto universal de Estado constitucional válido para sociedades post-conflicto tienen en común la necesidad de asegurar la justicia penal internacional en el proceso de reconstrucción democrática de estas sociedades. No se trata sólo de perseguir a los autores de graves violaciones de los derechos humanos y de los principios básicos del Derecho Internacional Humanitario, sino también, de incluir la reparación a las víctimas de graves violaciones de derechos

${ }^{50}$ Rodríguez CARrión, A., Lecciones de Derecho Internacional público, 2006, op. cit., pág. 81 .

${ }^{51}$ Cuyo máximo exponente es el artículo 3 del Estatuto del Consejo de Europa, firmado en Londres el 5 de mayo de 1949 y en el que hoy son parte cuarenta y siete Estados de Eurasia (800 millones de personas).

52 Parágrafo 628 del Informe de la Comisión Internacional en Darfour. 
humanos en un contexto de conflicto armado, entre las exigencias de una efectiva reconciliación nacional.

\section{CONCLUSIONES}

En un medio social escasamente vertebrado y poco institucionalizado como es la sociedad internacional, la soberanía de los Estados sigue siendo un principio constitucional. En el mundo globalizado en que vivimos, el paradigma de sociedad internacional coexiste con el de comunidad internacional. Ahora bien, para que exista una comunidad internacional es indispensable la presencia de intereses comunes así como un patrimonio común de valores. En este sentido, uno de los indicios que mejor reflejan la idea de comunidad internacional pos contemporánea es la nueva concepción de la soberanía que se hace responsable. Así pues, en estas páginas se ha abordado un tema clásico desde una perspectiva novedosa: la conceptualización en Derecho Internacional de un modelo de Estado constitucional en el que el papel de la soberanía ha de ejercerse en un contexto de obligaciones imperativas para los Estados en materia de represión y sanción de los graves crímenes contra el Derecho Internacional.

Así, frente a un modelo clásico de análisis formalista-descriptivo de la soberanía estatal, hoy día, ésta se percibe no tanto como un estatuto espacial y temporal, como una actitud vital que exigiría prestar atención al ejercicio de unos derechos y deberes, en especial, tratándose de las graves violaciones de los derechos humanos y de normas del Derecho Internacional Humanitario.

Desde esta perspectiva, la tesis defendida ha sido que se aprecia una clara tendencia a poner énfasis en el alcance de la justicia penal internacional en el proceso de reconstrucción conceptual universal de Estado constitucional a partir de una relectura de la noción de soberanía a partir de un triple eje: a) la legitimidad de los gobernantes (legitimacy); b) la intangibilidad de los derechos humanos fundamentales (intangibility); c) la rendición internacional de cuentas (accountability). 